\title{
Reasons and Decisions
}

\section{Citation}

Scanlon, Thomas M. Jr. 2006. Reasons and decisions. Philosophy and Phenomenological Research 72, no. 3: 722-728.

\section{Published Version}

http://dx.doi.org/10.1111/j.1933-1592.2006.tb00599.x

\section{Permanent link}

http://nrs.harvard.edu/urn-3:HUL.InstRepos:3708347

\section{Terms of Use}

This article was downloaded from Harvard University's DASH repository, and is made available under the terms and conditions applicable to Other Posted Material, as set forth at http:// nrs.harvard.edu/urn-3:HUL.InstRepos:dash.current.terms-of-use\#LAA

\section{Share Your Story}

The Harvard community has made this article openly available.

Please share how this access benefits you. Submit a story.

Accessibility 


\title{
Reasons and Decisions
}

\author{
T. M. Scanlon
}

Thinking How to Live is a splendid book. It is remarkably clear. It presents a novel and ingenious response to a difficult problem. It is thorough in exploring the implications and potential difficulties of this approach, and fair-minded in taking account of alternative views.

The central notion of the book is the idea of something's being "the thing to do." In ordinary English, the phrase, "X is the thing to do" can express either a judgment:

[R] $\mathrm{X}$ is what I have most reason to do

or a decision (what Gibbard calls the adoption of a plan):

[D] I will do X

Gibbard introduces " $\mathrm{X}$ is the thing to do" as a technical term, not a piece of ordinary English. But our reaction to his analysis will depend on how this term is to be understood, and there are passages in the book that suggest each of the interpretations I have mentioned. He says, for example, that Holmes' "conviction that packing is the thing to do is ... a fragment of a plan; it consists in planning now to pack," (75) and that "according to my stipulation, to think something the thing to do is to plan to do it." (153) These passages suggest that $[\mathrm{D}]$ is the proper interpretation of " $\mathrm{X}$ is the thing to do." But other passages suggest [R]. He says, for example, that "disagreement in plan" about whether the thing for Caesar to do on the Ides of March is to go to the Senate is disagreement about what Caesar, all told, has agent-centered reason to do. (68) And he 
says that "the concept of there being most reason all told to do X" that "amounts to my primitive concept of X's being the thing to do.” (191)

For an ideally rational person, and perhaps for Gibbard himself, $[R]$ and $[D]$ go together. When such a person concludes that $\mathrm{X}$ is what she has most reason to do, she will decide to do $\mathrm{X}$, and she will not plan to do $\mathrm{X}$ if she judges that she has most reason to follow some other course of action. But for most of us there is a significant distinction between $[R]$ and $[D]$. We can, for example, be quite certain that what we have most reason to do is to call the doctor today about a disturbing symptom, yet not even decide to call the doctor today, let alone do so. ${ }^{1}$

Gibbard considers the possibility of this kind of irrationality at two places in the book. In the first, he acknowledges that it seems false to say that if a person fails to do something then he does not believe, at that moment, that he ought to do it. Put in the terms I have been using: it seems false to say that if a person fails to do X, then he does not (then) accept that $\mathrm{X}$ is what he has most reason to do (that is, he does not accept [R].) The problem is that insofar as Gibbard does not distinguish between $[R]$ and $[D]$ he is committed to maintaining this apparently false claim. His response is that the cases in which this claim seems to be false - those in which it seems plausible that a person who fails to do $\mathrm{X}$ nonetheless believes that $\mathrm{X}$ is what he ought to do (or what he had most reason to do) — are cases in which the agent is "of more than one mind" about what he ought to do. If a person does not do X then, Gibbard says, there is a part of him that does

\footnotetext{
${ }^{1}$ John Hawthorne cites similar examples in his response to an article in this journal in which Gibbard presented some of the ideas that are developed more fully in this book. See Hawthorne, "Practical Realism?" Philosophy and Phenomenological Research 64 (2002), 169-178, esp. p. 171.
} 
not accept that $\mathrm{X}$ is what he ought to do. So Gibbard is committed to a strong link between the ought-judgments that a person accepts and the actions he or she performs only in when the person is "of one mind" about these judgments. He writes, "For a crucial sense of 'ought', I say, the following holds: if you do accept, in every relevant aspect of your mind, that you ought right now to defy the bully, then, you will do it if you can." (153)

Perhaps this is so. If I fail to do X, and not through mere inadvertence, or because I have been knocked unconscious, then presumably this is because there is something about not doing X that I find sufficiently attractive to act on. So I am not "of one mind" in the sense that there is "a part of me" that finds not doing X more attractive than doing $\mathrm{X}$. When $\mathrm{X}$ is "defying the bully" it would perhaps be surprising if this were not the case. But even if this is the case it does not follow that I am not "of one mind" about the judgment that $\mathrm{X}$ is what I have most reason to do. Indeed, the main function of judgments like $[R]$ is to identify where the balance of reasons lies in cases in which we see the force of reasons on both sides. In such a case, concluding, even definitively and without any doubt, that the balance of reasons supports doing $\mathrm{X}$ does not eliminate these other reasons, or extinguish their appeal. Unequivocal acceptance of $[R]$ does not require one to be "of one mind" in the stronger sense that Gibbard describes. So the implausible consequences of identifying $[R]$ with $[D]$ remain.

The second passage in which Gibbard discusses this problem raises a different point, about what it is to plan to do something in the sense that he has in mind. Here Gibbard discusses the case of "a binge alcoholic who every Saturday night comes to want 
to get drunk, but who spends the week hoping desperately that he'll get through Saturday night on the wagon." (51) Gibbard says that the alcoholic "can ask himself what to do if it's Saturday night and he comes to crave a drink; he can ask this knowing what he will in fact do. This is what I am calling 'deciding hypothetically' ..." Gibbard acknowledges that the answer that the alcoholic gives, on Wednesday, to the question "what to do next Saturday" does not constitute a "fully-fledged plan for what to do." This is because he cannot make this plan effective and knows that he can't. As Gibbard says a few pages earlier (49), (fully-fledged) contingency planning has two aspects. The first is that "one asks oneself what to do if faced with that contingency, and comes to an answer. As we might put it, he comes to a view on what to do in that contingency." The second aspect is that "he expects that that thing is what he really will do if the contingency arises."

'Expects' may be a little too strong. We can decide to do things - adopt plans to do them-even if we expect that we will not be able to follow through. I can, for example, decide to go on a diet, or to take up an exercise regimen, even if I strongly suspect that I will fail. But what Gibbard says about the drunk is stronger: that on Wednesday he knows what he will in fact do on Saturday, namely that he will get drunk. If he knows this, then it does not seem to me that we can say that he decides, or plans, not to drink.

Gibbard says that it is the first aspect of contingency planning that chiefly concerns him. (49) And he in effect drops the second aspect (the expected effectiveness of the plan in shaping future conduct.) This necessary not only to handle cases like that of the drunk, but also in order to allow for interpersonal disagreement about "the thing to 
do." Gibbard says, for example, that Holmes may disagree with Mrs. Hudson about the thing for her to do if Moriarity is near. She thinks it is to call the police. He thinks otherwise. Gibbard interprets this as a case of "disagreement in plan.” Mrs. Hudson's judgment about the thing to do if Moriarity is near consists in a plan to call the police in this eventuality. Holmes's conflicting judgment is a conflicting plan about what to do in the hypothetical case in which he is Mrs. Hudson in the circumstances envisaged. Gibbard is quick to acknowledge that "in some ways, to be sure, this isn't full-fledged contingency planning." Even leaving aside the fact that Holmes is certain he will never be in Mrs. Hudson's exact situation, there is the fact that the "second aspect" of planning is not fulfilled in this case: his own thinking does not affect what she will do. "She cannot act on his thinking in the way the he can act on the planning he is now engaged in." (50)

So when Gibbard says that to reach a conclusion about "the thing to do" in certain circumstances is to decide, or plan, what to do in that hypothetical case, we have to understand 'decide' and 'plan' in a rather thin sense, which leaves out an important aspect of our ordinary use of those terms.

The evident difference between deciding what to do and reaching a conclusion about what others have most reason to do is an important part of what drives some of us to see a significant difference between [D] and [R]. Making a decision about what to do and adopting a plan are things that one does for oneself, and that one can (in the full sense) only do for oneself. Therefore no one would think that when " $\mathrm{X}$ is the thing to do" is understood as expressing a decision, or the adoption of a plan, it expresses something that can be true or false. [R], by contrast, seems to express a claim about something 
arguably independent of the speaker - whether the balance of reasons favors doing X.

This is something that two people can have conflicting opinions about whatever they may have decided to do themselves. [R] is therefore much more naturally understood as expressing something like a belief, the kind of thing that can be true or false. ${ }^{2}$

Gibbard reduces the difference between $[R]$ and [D] by thinning down the ideas of decision and plan by dropping the "second aspect." This gives rise to a question about where this leaves us: How much of [D] is left? Or, alternatively, why not forget about [D] altogether and focus simply on $[\mathrm{R}]$ as the interpretation of " $\mathrm{X}$ is the thing to do"? Doing this would, I believe, be quite compatible with a central part of the analysis Gibbard offers in Thinking How to Live. But this move would also seem to threaten what is, from his point of view, a main point of that analysis. I want to say something about each of these claims in turn.

The technical centerpiece of Thinking How to Live is a semantics for statements like " $\mathrm{X}$ is the thing to do" and for complex statements like

(1) Either packing is now the thing to do, or by now it is too late to catch the train anyway.

which mix claims about what to do with ordinary descriptive statements. The basic notion of this semantics is that of a maximally decided state, or hyperstate. (54) This is a state of mind in which a person has settled on what is "the thing to do" in every conceivable situation. The content of such a state of mind is given by what Gibbard calls a hyperplan,

${ }^{2}$ As Hawthorne says, "Second, when I come to a conclusion about what someone else is to do, I do not, plausibly, express a decision: I straightforwardly express a belief." "Practical Realism?" p. 171. 
which specifies the thing to do in each situation. Such a plan must be complete: for every alternative available in a possible situation, the plan must either reject it or reject rejecting it. ${ }^{3}$ Just as the content of a factual statement can be characterized in terms of the set of possible worlds in which it is true, the content of a claim about "the thing to do" (or of any combination of such claims) is given by the set of hyperplans that it is consistent with. Now call any pair $<w, p>$ of a factual possible world $w$ and a hyperplan $p$ a fact-plan world. The content of mixed statements such as (1) is given by the set of fact-plan worlds in which they obtain. Gibbard notes that for those who prefer to avoid speaking of worlds of this kind, the content of these statements can be characterized simply in terms of the hyperstates that allow them (taking these states of mind to be completely "decided" regarding all factual matters as well as regarding "the thing to do.") "These two ways of speaking - (i) in terms of planning, believing and ways of thinking that intertwine the two, and (ii) of facts, plans, and content that intertwines the two-are isomorphic to each other." (57)

This apparatus provides a clean solution to the "Frege-Geach problem" of explaining how, if statements about what is "the thing to do" are not normal fact-stating utterances, they can nonetheless figure in mixed statements like (1) and in inferences, such as when we conclude from (1) and from

(2) It is not now too late to catch the train

that (3) Thing to do now is to pack.

${ }^{3}$ I discuss the reasons for this complication in note 8 below. 
This formal apparatus leaves it open exactly how we are to understand " $\mathrm{X}$ is the thing to do". That is to say, it is neutral as between [R], a "full-fledged" interpretation of [D], and anything in between. All that is necessary to have a hyperplan is that in each situation some alternative is decisively identified as the thing to do. Pushing things in one direction, suppose that we think of " $\mathrm{X}$ is the thing to do" in terms of [D], taking it to express as "fully-fledged" a decision as seems plausible. As I have said, no one, however much of a realist, would take [D] so understood as purporting to state any kind of fact. This shows that although the apparatus of fact-plan worlds allows us to speak of normative judgments in terms of something that ha a structure parallel to that truth and falsity, it does not establish any kind of realism (as indeed Gibbard would be the first to emphasize.)

Pushing things in the opposite direction, the analysis works just as well if we interpret " $\mathrm{X}$ is the thing to do" entirely as a claim about reasons, leaving out any idea of decision or plan. In this case there may be less need for the exercise since, as I said, claims about reasons are more naturally read, naively, as making claims that are true of false. But this would also, I think, vitiate an aim that is important for Gibbard. To simply take the idea of a reason at face value, as a starting point, he says, is to leave that notion unexplained. (191) It is a primary aim of his analysis to provide the needed explanation. So we need to consider in more detail the kind of explanation that Gibbard seeks to provide, and the degree to which giving this explanation requires us to move away from $[R]$ in the direction of [D]. 
What is it about reasons that needs to be explained? I believe that Gibbard has two things in mind. First, as to content, he wants to explain how we can understand claims about reasons without being committed to metaphysically "queer" entities or nonnatural properties. Second, he feels that the link between these judgments and subsequent action needs to be explained. If statements about reasons simply express a kind of belief, it seems mysterious how this has any bearing on what the agent does.

Two things should be mentioned about the second concern, for purposes of future discussion. The first is that conclusion about what the balance of reasons supports are "connected" not only with action, or changes in intention, but also with other things such as changes in belief, and readiness to accept the justifications that others offer for their actions (even if these actions are not "what one would have done in their place.") The second is that there is a question about what the supposed "connection" is supposed to be. Is the thing to be explained a causal connection, how a certain kind of mental state can produce another? Or is it a normative connection? Is the thing to be explained why a certain kind of state must be accompanied by another, unless something is amiss? For example, why it will be accompanied by the other insofar as the agent is rational (or insofar as he or she is not irrational)?

In the section I have just referred to, in which Gibbard speaks of the importance of not leaving the concept of a reason unexplained, he describes his explanatory strategy in the following way. We should distinguish, he says, between a purely psychological notion of "a person's weighing a consideration toward taking a course of action" and a similar sounding normative notion of "a consideration's weighing in favor of a course of 
action.” The expressivist strategy, he says, is to start with the psychological notion and explain the normative one in terms of it. (190)

How does the "planning" account that Gibbard develops fit this strategy? It seems to do so as follows. Planning to do $\mathrm{X}$ is the psychological attitude in terms of which the normative attitude of regarding $\mathrm{X}$ as the thing to do is supposed to be explained. If " $\mathrm{X}$ is the thing to do" expresses a plan to do X, then there is no need to see it as expressing a belief in some non-natural fact, or ascribing to X some non-natural property of "to be doneness." Similarly, the normative content of other normative concepts that we employ in deliberation, such as 'obligation', or 'disloyal', can be explained by the fact that they, like the concept of "being the thing to do," are "plan-laden." That is to say, their noninverted commas use presupposes that acceptance of certain plans about how to act. They therefore do not refer to special non-natural properties.

The connection with action is explained by the fact that, as Gibbard says in discussing the example of the bully, "To think, for instance, that the thing to do now is to defy the bully who torments me is to plan to defy him. And planning right now right now to defy him right now, at this very moment, amounts to setting out to do it." [153]

Both parts of this explanation depend on the notion of a plan. So to draw back, as I proposed, from $[\mathrm{D}]$ to $[\mathrm{R}]$ would seem to involve giving up on this explanatory strategy. So the tension Gibbard faces is this: His explanatory strategy requires his notion of $\mathrm{X}$ being "the thing to do" to express the acceptance of a plan to do X, not merely the judgment that $\mathrm{X}$ is what the balance of reasons favors. But if " $\mathrm{X}$ is the thing to do" expresses a full-fledged decision to do $\mathrm{X}$, this forges too close a link with action. It rules 
out weakness of will, and does not provide a plausible account of argument and disagreement with others about what they have most reason to do. Gibbard responds to the latter problem by weakening the notion of decision that he is relying on. (As I have put it, by backing off from [D] in the direction of [R].) But he cannot go too far in this direction without sacrificing his explanatory strategy.

The difficulty that akrasia presents for his analysis is brought out by considering how to answer the question I mentioned above about the nature of the connection between normative judgment and action. The connection that Gibbard's account forges seems to be neither causal nor normative, but definitional: if a person does not set out to do $\mathrm{X}$ (that is, if he consciously declines to do this) then he does not, right now, plan to do it right now. This is plausible as far as plans are concerned. But not, as I have said, plausible as a claim about [R]. Judging that what I have most reason to do right now is to defy the bully, and getting myself, right now, to defy him, seem to be two different things. Gibbard acknowledges this when he weakens the parallel definitional claim about 'ought' by inserting the qualifier 'normally': “a state of mind isn't a judgment of ought all told if it isn't a state of mind that normally issues in action." (154)

The problem about judgments about other people's reasons is an instance of a larger phenomenon that I have mentioned above. Judgments about reasons have connections with many attitudes: not only with plans (with changes in intention) but also with changes in belief, changes in feelings such as resentment, and changes in one's willingness to accept the justifications that others offer for their actions. In addition, as Gibbard recognizes, conclusive judgments about the thing to do all told are not the only 
judgments we make about the reasons we have. We also make judgments about which factors count as reasons at all (which ones are among the factors must be taken into account in order to reach an "all told" conclusion.)

One might try to respond to these problems by broadening the range of things about which we have plans to include more than actions in the usual sense. For example, we might say that to regard $\mathrm{X}$ as a reason for something is to plan to weigh it in favor of that thing; and to regard something as a good justification for a certain action is not only to plan to so act if one were to be in a situation in which that justification would apply but also to plan to accept that justification when it is offered by others.

One problem with this move is that it does not solve the problem of weakness of will. Someone can, for example, accept that a consideration weighs in favor of some action but fail to give it this weight. But the "planning" interpretation would seem to rule this out.

A second thing to notice is that many of the attitudes that figure as objects of our plans on this account have an apparently normative character. What is it to plan to accept a justification if not to regard it as a good justification? And to plan to weigh a consideration in favor a certain decision is not just to plan to be influenced, for example, by putting oneself in circumstances in which one will be susceptible to this influence. One can plan to be influenced in favor of a decision by things that one does not regard as weighing in favor of it. So it looks as if planning to weigh something in favor of a decision is planning to take it as supporting, or partially justifying that decision. And 
planning to do that, if sincere, would seem to involve thinking, now, that it has that justificatory force.

I do not myself regard this as a problem, and I want to argue that Gibbard should not see it as a problem either. It seems to me that the difficulties I have described, particularly the problem of allowing for akrasia, do not arise from the expressivist strategy of giving a (non-reductive) psychological account of normative attitudes but rather from the attempt to force too much of this explanation through the single notion of a plan. My suggestion is that the strategy could be more plausibly carried out if he were to broaden the range of notions that figure in his psychological explanation. These will include notions of a more explicitly normative character than the notion of a plan, such as the idea of seeing something as a reason. But we can distinguish here, just as Gibbard proposes, between the normative content that these notions have when one employs them in deliberation and their descriptive employment in a psychological account of deliberating agents.

Gibbard introduces this distinction when he is discussing the idea of a consideration's being a reason for something or, as he puts it, "weighing in favor of that thing." The psychological state of "weighing factor R in favor of doing X" amounts, he says to "calculating what to do on a certain pattern, a pattern we could program a robot to mimic." What the robot does, he imagines, is to attach positive and negative numbers ("indices") to each pair $<\mathrm{R}, \mathrm{X}>$ of a factor $\mathrm{R}$ and action $\mathrm{X}$. These indices represent the degree to which the factor R "weighs in favor of" the action X. The robot then (presumably - Gibbard does not say this explicitly) takes account of which factors 
actually obtain. It then sums up the related factors for each action and performs the action that is supported by the highest sum of such indices. As Gibbard acknowledges, this description of what the robot "does" requires ascribing content to features of the robot's circuitry. But his point, I take it is that the idea of R's weighing in favor of X (for the robot) is captured by the idea of R's figuring in a certain way in determining the robot's motions.

"We ourselves," Gibbard says, "can settle what to do in a like way, not toting up numbers explicitly perhaps, but proceeding as if we did. When we do, I say that we are weighing considerations." This expressivistic style of explanation, Gibbard says, explains the state of mind of believing something to be a reason to do $\mathrm{X}$ as “one's weighing that factor in favor of doing $\mathrm{X}$ - and to do so is to form contingency plans on a certain pattern.” (190-191)

But (staying here merely at the level of psychological description) what we do is importantly different from what the robot does. We are disposed for or against various courses of action because of the way certain factors are represented in our circuitry. But we also have views as to which factors "weigh in favor of" various actions. These two generally go together, but they do not always do so - the degree to which certain factors in fact dispose us to action do not always coincide with our views as to their reasongiving force (this is a root of the phenomenon of akrasia.) A psychological account that ignored our views and attended only to how we are disposed would be a very incomplete as a psychological account of the idea of believing something to be a reason. 
An adequate account, I suggest, would have to include more. We have beliefs, intentions, plans, and other attitudes. We have views about which considerations are reasons for ("weigh in favor of") various beliefs, plans and attitudes, and views about how these weighings come out. The statements I have just made are simply statements about our psychological states. It would not make sense to attribute all of these states to us, however, if our mental life did not exhibit a certain pattern: in particular if the attitudes we form were not normally responsive to our judgments about the reasons for them. ${ }^{4}$ To say that this does normally happen, and that the attribution of these attitudes does therefore make sense, is just to say that we are rational agents, in a (so far) purely descriptive sense - that is, that we are agents who exhibit a certain kind of psychological organization.

The relation between $[R]$ and $[D]$ is one instance of the kind of regularity I am discussing. A rational agent who accepts the judgment expressed in $[\mathrm{R}]$ will normally make the decision expressed in [D] as well. (Such an agent will do so insofar as he or she is not irrational.) But the two states are not the same. The can come apart.

Does this explanation merely help itself to an unexplained notion of a reason? It seems to me that it does not. Rather, it helps itself to the idea of believing something to be a reason, and offers a kind of explanation of this state by locating it within a larger psychological pattern. This is the style of explanation that Gibbard says he is following in explaining "weighing in favor of" by describing a certain pattern through which contingency plans are formed. The pattern I have described employs a richer set of

${ }^{4}$ Compare Gibbard's remark that "a state of mind isn't a judgment of ought all told if it isn't a state of mind that normally issues in action." (154). 
psychological notions. But this does not render the explanation question-begging. Nor do I see how an account that left these notions out could be an adequate account of our process of forming such plans.

This account does not employ the normative idea of being a reason by making claims about which things are reasons. But it does not, on the other hand, explain the normative force of the idea of a reason. Gibbard, as I understand him, does not attempt to do this either. He agrees, I think, that this normative force does not appear except when one employs these ideas in the course of deliberation. What he seeks to provide is an account of reasons "from the outside" by offering a psychological description of the process of reasoning and its place in our lives. An account of the kind I have described would do the same.

Although such an account would fit the pattern that Gibbard calls the expressivist style of explanation, it leaves the question of expressivism itself to some degree open. It would remove one source of pressure toward an expressivist interpretation of normative terms. ${ }^{5}$ This is because there is no need, on an account of the kind I am describing, to give judgments about reasons an expressivistic reading in order to explain their "connection with action." This connection consists in such things as the fact that if a person judges $\mathrm{X}$ to be what he has most reason to do then he generally forms the intention to $\mathrm{X}$, and (absent a change of mind) does $\mathrm{X}$ when the time comes.

\footnotetext{
${ }^{5}$ One source of pressure in the opposite direction, which this account might leave unaltered, is the case of judgments about the reasons that other people have, which, as I have said, are more naturally understood in cognitivist terms.
} 
On the account I am proposing this fact is explained holistically. ${ }^{6}$ It is part of being a rational agent that one is constituted in such a way that these connections generally hold. In order to account for these connections we need not interpret judgments about reasons as having any special non-cognitive force (as expressing imperatives, for example, or the acceptance of plans.) These regularities are due as much to the special responsiveness of the states affected — the beliefs, plans, and actions of a rational agentto the agent's assessment of the reasons for them as they are to any special character of the latter judgments. The kinds of attitudes (judgments about reasons and attitudes such as plans) are properly understood only in relation to one another. As Gibbard says, an ought judgment (a conclusion about reasons) would not be an ought judgment if it did not normally have connections with what the agents plans and actions. But, equally, we could not properly attribute beliefs plans and actions to an agent if these were not normally responsive to her conclusions about reasons for them.

Instances of akrasia pose no special problem, on this account. In order for a being to be a rational agent, it is not required that these connections hold invariably, but only that they hold in general. These connections are, at one level causal: they hold in virtue of the way the agent is constituted. But it can also be said that will they hold insofar as the agent is (fully) rational. This suggests that they are also normative connections. It is unclear exactly what kind of normativity is involved in such appeals to the idea of

\footnotetext{
${ }^{6}$ I discuss the following ideas in "Metaphysics and Morals," Proceedings of the American Philosophical Association 77 (2003), 7-22.
} 
rationality. ${ }^{7}$ One thing that I believe is clear, however, is that claims of the kind I am discussing about what an agent must do insofar as he or she is not irrational do not involve claims about which things are reasons. To invoke the idea of rationality in this way is therefore not question-begging in the present context.

An external account of normative attitudes of the kind I am proposing would not give the idea of a plan the centrality that Gibbard assigns it. (For that reason, adopting this approach might seem to him to be throwing the baby out in order to keep a little bath water.) But this approach would, I believe, be compatible with an account of the semantics and logic of normative judgments very much like the one Gibbard offers. The idea of a fully decided state would have to be extended to include not only decisions about what is to be done in every situation but also decisions about which considerations count in favor of which attitudes, and in what degree. I assume that these modifications could be worked out. The content version of this semantics would perhaps better be called a "factual-normative world" rather than a "fact-plan world."

This enrichment bears on a problem that Gibbard confronts in defining fully decided states. To be in such a state, one might say, is to have decided, for every conceivable situation, which alternative to choose in that situation. But "choose" here could be understood in either a weaker or a stronger way. On the weaker interpretation, the idea of having chosen an alternative in each situation simply means that one alternative in each situation is identified as "selected." This would leave open the

\footnotetext{
${ }^{7}$ I discuss this question further in "Structural Irrationality," to appear in a volume of essays in honor of Philip Pettit, edited by Geoffrey Brennan, Robert Goodin, and Michael Smith.
} 
possibility that in at least some cases all one did was to pick an alternative, perhaps arbitrarily and out of indifference, the way that Buridan's ass might have done. On the stronger interpretation, to choose an alternative in each situation is to identify it affirmatively as "the thing to do."

Gibbard wants to be able to make this distinction, and it is the stronger notion that he wants to use in defining fully decided states. As he writes, "It is in the nature of planning, after all, to distinguish rejecting an alternative by preference from simply not choosing it in that, from indifference, one chooses another. Rejecting an alternative is something more than just taking a different alternative when there is more than one alternative that one doesn't reject by preference." (54)

He worries that it might seem necessary, in order to make this distinction, to suppose that the planner attributes to some alternatives, but not others, the non-natural property of being "okay to take" or "admissible," and others the property of being "non to be taken." (55) His solution is to make the distinction in terms of the logical relations between decided states. Instead of defining a hyperstate as one in which the planner divides alternatives into those that are rejected and those that are allowed, he adopts the slightly more complex formulation which requires the planner either to reject an alternative or to reject rejecting it. The difference between "allowing" (not rejecting) an alternative rejecting rejecting it is simply that the latter is incompatible with rejecting it on some other occasion, whereas the former is not. (56)

This solution is entirely coherent, and the distinction between choosing an alternative and rejecting rejecting is one that needs to be made. But if the way of dealing 
with the idea of a reason that Gibbard proposes on page 190 is successful, it does not seem that he need have worried about the cognitivist implications of the idea of choosing something for a reason, as opposed to picking it out of indifference. To attribute this state to a planner - to say that she weighs a certain factor in favor of doing $\mathrm{X}$ - is not necessarily to attribute metaphysical views to her but just, as Gibbard says, to say that she "forms contingency plans on a certain pattern." (191) If she regards some set of considerations as conclusive reason for doing $\mathrm{X}$, then she will be in a state of mind that is incompatible with not doing $\mathrm{X}$ on any occasion in which these considerations are present. That is to say, she will reject rejecting it. But I do not see why Gibbard needs, on his own analysis, to rely solely on this notion.

Enriching Gibbard's semantics in the way I have proposed would give us a way of assigning truth-like values to judgments about reasons, but it would not, as I have said, amount to a serious form of realism. The style of explanation of normative attitudes that I have been proposing would not, I believe, involve require any commitment to queer nonnatural properties. I leave it open, however, whether some non-cognitivist reading of these statements would be necessary in order to avoid such commitment. This is something about which expressivists and minimalist normative realists might continue to disagree.

I offer this proposal not as a Trojan horse for normative realism but rather as a kind of middle position, in which the aims of Gibbard's admirable book might be more fully realized. 